\title{
Eosinopenia: An early diagnostic marker of COVID-19
}

\section{Farhana Tahseen Taj, S. Devipriya}

Department of Dermatology, Venereology and Leprosy, Jawaharlal Nehru Medical College, KLE Academy of Higher Education and Research, Belgaum - 590010, Karnataka, India

Corresponding author: Farhana Tahseen Taj, MBBS, MD (DVL), E-mail: farhanahaveri@gmail.com

\begin{abstract}
Background: Coronavirus disease 2019 (COVID-19) is a global pandemic that has affected over two hundred countries and led to the increasing challenge of identifying, diagnosing, and treating patients. An effective early diagnostic marker is necessary for the identification of affected individuals, which would further aid in helping the prognosis. Objective: The aim was to study the diagnostic role of the eosinophil count in COVID-19 infection. Methodology: Thirty-five COVID-19 cases, confirmed either by RT-PCR or HRCT (high-resolution CT scan) were included in this cross-sectional study. Results: Out of the 35 patients, 26 (74.3\%) had an eosinophil count of 0 , six $(17.1 \%)$ had a count of $1-2$ esinophils, and one had a count of 4. Conclusion: The absence of eosinophils in the routine complete blood count examination may certainly help in the early identification of a COVID-19 infection. Early identification may help in early therapeutic management and hence prevent further deterioration of the patient's health.
\end{abstract}

Key words: COVID-19; biomarkers; eosinopenia; eosinophil count

\section{INTRODUCTION}

Coronaviruses have led to the outbreak of diseases in East Asia and the Middle East in the past decades. Lately, a new coronavirus virus has emerged in Wuhan, China, whose genome sequencing differs from previous strains and has been named severe acute respiratory syndrome $\mathrm{CoV}-2$ (SARS-CoV-2) [1]. This virus strain causes COVID-19 (coronavirus disease 2019), which emerged at the end of 2019 [1]. COVID-19 was declared a global pandemic by the WHO on March 11, 2020 [2]. As of February 8, a total of 106,765,682 cases and 2,328,912 deaths have been reported by the WHO [3]. Previous studies have suggested an association between a decrease in the eosinophil count and acute respiratory diseases seen in COVID-19 infection [4-7]. The aim of our study was to find the association between the eosinophil count and COVID-19 in patients admitted as confirmed cases of COVID-19.
Eosinophils constitute 6\% of bone marrow nucleated cells [8]. Eosinophils are potent proinflammatory cells, mainly because of the granules that contain cytotoxic proteins [9]. Although a blood cell, it is also present in various tissues, such as the gastrointestinal tract and the lungs $[9,10]$. Eosinopenia is the decrease in eosinophils, less than $0.01 \times 10^{9} / \mathrm{L}[11]$. It has been found that the eosinophil count decreases during acute inflammation and increases during recovery from infection [12]. Since the emergence of COVID-19, there have been numerous reports of biomarkers involved in the disease, including C-reactive protein (CRP), interleukin-6 (IL-6), an increased ferritin level, the white cell count (WBC), lactate dehydrogenase (LDH), D-dimer, the platelet count, ALT, AST, an increased prothrombin time, highsensitivity troponin, and renal markers [11]. Previous studies suggest that eosinopenia occurs as a response to acute inflammation or due to another systemic reaction 
induced by its virtue. The initial decrease in the eosinophil count was attributed to the sequestration of circulating eosinophils. Migration may happen in an inflammatory site due to the release of chemotactic factors [11].

\section{METHODS}

\section{Study Design and Participants}

This was a cross-sectional study that included 35 patients with COVID-19, confirmed either by RT-PCR or HRCT, prior to the initiation of any treatment. Patients with a CO-RADS score of 4, 5, and 6 in HRCT were considered positive. Critically ill patients and patients who were suspected cases of COVID-19 were excluded. The study was approved by the institutional ethical committee. Informed consent was not taken as this study included only routine evaluation. Information regarding demographics, clinical manifestations, vitals, laboratory data, and clinical progression of the disease and treatment were collected.

\section{Statistical Analysis}

Categorical variables were reported as numbers and percentages.

\section{RESULTS}

All 35 patients collected were cases of COVID-19, confirmed either by RT-PCR or HRCT. The median age was 62 years. Among them, 7 patients belonged to the age group of 30-49 years, 16 to the age group of 50-69 years, and 10 to the age group of 70-89 years (Fig. 1). 27 were males and the remaining 8 were females (Fig. 2). A majority of the patients presented with fever, dry cough, and myalgia. Other symptoms included a sore throat, dyspnea, and anosmia. 26 patients $(74.3 \%)$ were found to have an eosinophil count of zero, $6(17.1 \%)$ were found to have an eosinophil count of $1-2$, and 1 (2.9\%) had an eosinophil count of 4 (Fig. 3).

\section{DISCUSSION}

Coronaviruses are highly enveloped, positivesense RNA viruses with a high mutation rate and infectivity [1]. They are important zoonotic pathogens infecting animals and humans [1]. The clinical features may vary from asymptomatic through severe acute respiratory distress to multiorgan failure and death $[13,14]$. Even if the patient is asymptomatic, they are still capable of transmitting the virus [13]. The clinical manifestations include fever, myalgia, dry cough, a sore throat, headache, dyspnea $[13,14]$, as well as severe manifestations such as hypoxemia, confusion, chest pain, and pneumonia, with some cases requiring intensive care unit (ICU) admission and mechanical ventilation. Diarrhea, anosmia, and ageusia have also been reported in several studies $[15,16]$

There is the emergence of interest in the topic of eosinopenia as a biomarker of COVID-19 infection [11]. A response to acute inflammation causes the release of chemotactic factors into circulation, leading to a rapid and persistent decrease in circulating eosinophils $[11,14,17]$. There is also an association of adrenal corticosteroids and epinephrine, as it increases in acute stress, with the occurrence of eosinopenia [13].

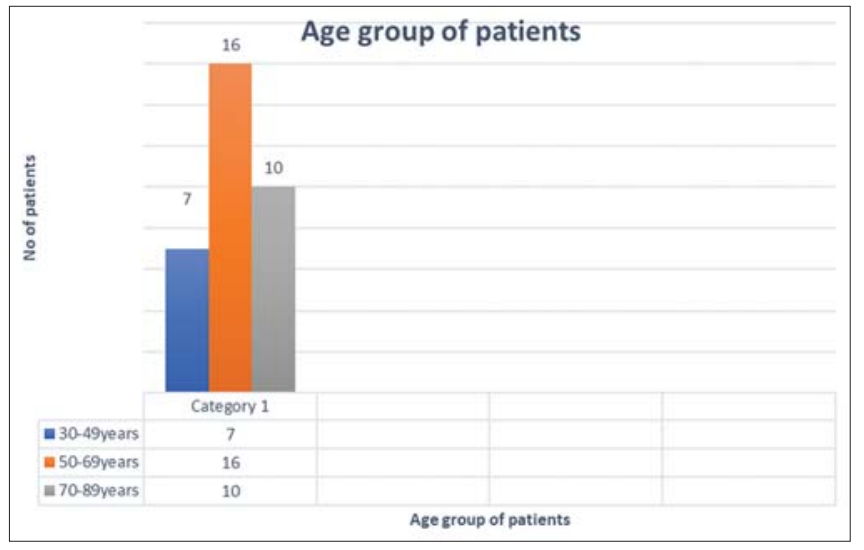

Figure 1: Age distribution of the patients.

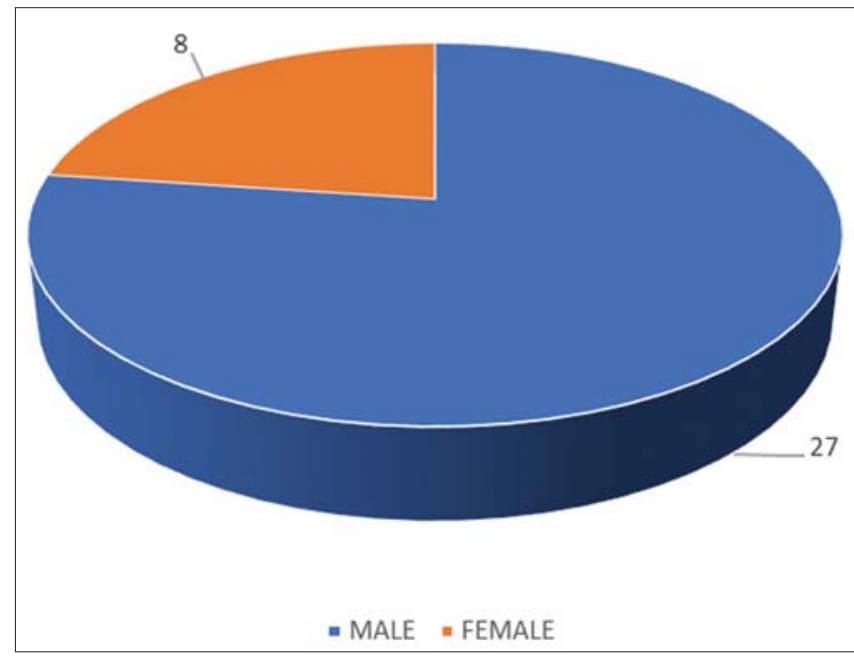

Figure 2: Gender distribution of the patients. 


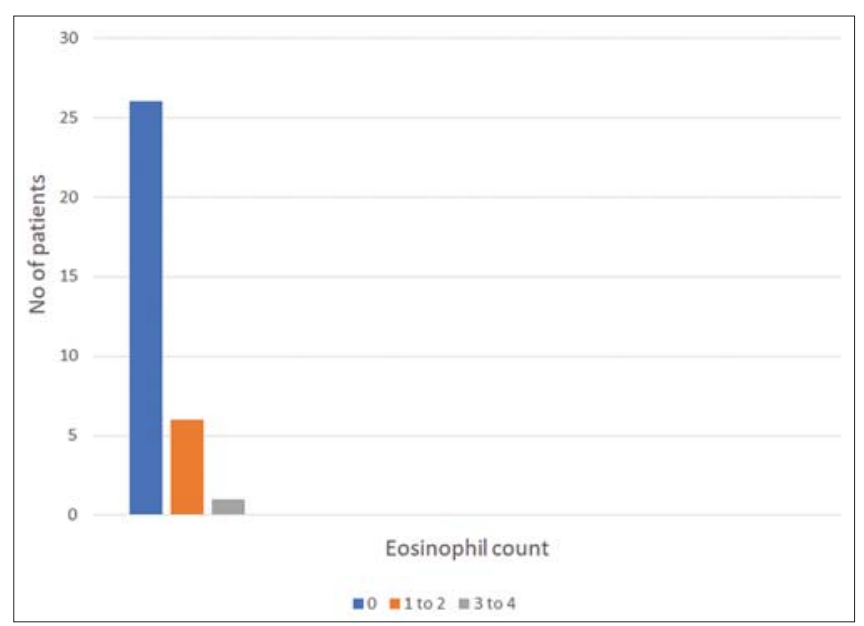

Figure 3: Eosinophil count in the COVID-19 affected patients.

\section{EOSINOPENIA IN RESPIRATORY TRACT DISEASES}

Human eosinophils may express toll-like receptors (TLR) such as TLR3, TLR7, and TLR9 that can detect molecular patterns $[9,18]$. TLRs may help eosinophils to identify coronaviruses and lead to degranulation, the release of cytokines, and nitric oxide (NO) production [9]. Previous studies show a direct antiviral effect of nitric oxide on parainfluenza virus and RSV [9,19]. Eosinophils may also produce extracellular DNA traps in response to viral diseases such as RSV [9]. Eosinophils may mobilize preformed granules of Thl cytokines, such as IL-12 and IFN-g, which helps in the antiviral immune response [9,20]. Human eosinophils express MHC-II molecules and costimulatory molecules and may also act as antigenpresenting cells for viral antigens, thereby causing T-cell activation and the release of cytokines [9].

\section{EOSINOPENIA IN COVID-19}

The cause of the decrease in eosinophils in COVID-19 is multifactorial [9]. The development and maturation of eosinophils occur in the bone marrow under exposure of myeloid precursors to IL3, GM-CSF, and IL5 [11]. The suggested pathophysiology of eosinopenia includes the decrease in IL-3, IL-5, and GM-CSF, leading to a decrease in the eosinophil count, as these three cytokines regulate the production of white blood cells, and resulting in sepsis [11]. Other mechanisms are the inhibition of eosinophils from the bone marrow and eosinophil apoptosis due to type 1 interferon release during acute infection [9]. Coronaviruses target IL-33, which is responsible for the activation of eosinophil in the airways, bone marrow, and ciliated epithelial cells. IL-33 is also involved in group 2 innate lymphoid cell activation, which in turn produces IL-5 and IL-13 [21]. Previous studies have found no increase in the eosinophil count in the lung tissue in COVID-19 patients [9,22].

Li et al.. conducted a study on 989 confirmed cases of COVID-19, in which eosinopenia $(<0.02109 / \mathrm{L})$ was present in $74.7 \%$, compared to the controls (31.3\%) [4]. Bass et al.., by using chemotactic factors of acute inflammation, were able to induce a decrease in the eosinophil count in rabbits and in humans. In a study conducted by $\mathrm{Hu}$ Yun et al.., out of 32 COVID-19 patients, 66\% showed a decreased eosinophil count [7].

\section{CONCLUSION}

Because COVID-19 follows an unpredictable course and may lead to deadly complications, there is a need for its early identification. The eosinophil count may be used as its early and low-cost indicator. In our study, around $71.4 \%$ of the hospitalized patients had an eosinophil count of zero at the time of admission. The estimation of the eosinophil count may help in early therapeutic management. However, only several studies have been done in this regard. The relationship between the eosinophil count and COVID-19 infection needs more exploration.

\section{ACKNOWLEDGMENTS}

All authors contributed substantially to the concept and the collection, analysis, and interpretation of data. We would like to acknowledge all healthcare workers involved in the diagnosis and treatment of COVID-19 patients.

\section{Statement of Human and Animal Rights}

All the procedures followed were in accordance with the ethical standards of the responsible committee on human experimentation (institutional and national) and with the 2008 revision of the Declaration of Helsinki of 1975.

\section{Statement of Informed Consent}

Informed consent for participation in this study was obtained from all patients. 


\section{ABBREVIATIONS}

SARS-CoV-2: severe acute respiratory syndrome coronavirus 2

COVID-19: coronavirus disease 2019

WHO: World Health Organization

RT-PCR: reverse transcriptase polymerase chain reaction

HRCT: high-resolution computed tomography

CO-RADS: COVID-19 Reporting and Data System

CRP: C-reactive protein; WBC: white blood cell;

LDH: lactate dehydrogenase; ALT: alanine transaminase;

AST: aspartate aminotransferase

RNA: ribonucleic acid; DNA: deoxyribonucleic acid

TLR: toll-like receptor; NO: nitric oxide; IFN-g: interferon gamma; GM-CSF: granulocytemacrophage colony-stimulating factor; IL: interleukin RSV: respiratory syncytial virus

MHC: major histocompatibility complex

\section{REFERENCES}

1. Dhama K, Khan S, Tiwari R, Sircar S, Bhat S, Malik YS, et al.. Coronavirus disease 2019-COVID-19. Clin Microbiol Rev. 2020;33:e0028-20.

2. WHO Director-General's opening remarks at the media briefing on COVID-19 - 11 March 2020: World Health Organization; 2020. Available: https://www.who. int/dg/ speeches/detail/who- director- general- s- opening-remarksat- the- media- briefing- on- covid- 19- 11- march- 2020.

3. COVID-19 coronavirus pandemic: Worldometer, 2020. Available: https://www.worldometers. info/coronavirus/\# countries.

4. Li Q, Ding X, Xia G, Chen HG, Chen F, Geng Z, et al.. Eosinopenia and elevated C-reactive protein facilitate triage of COVID-19 patients in fever clinic: A retrospective case-control study. EClinicalMedicine. 2020;23:100375.

5. Tan Y, Zhou J, Zhou Q, Hu L, Long Y. Role of eosinophils in the diagnosis and prognostic evaluation of COVID-19. J Med Virol. 2021;93:1105-10.

6. Tanni F, Akker E, Zaman MM, Figueroa N, Tharian B, Hupart KH. Eosinopenia and COVID-19. J Am Osteo Asso. 2020;120:504-8.

7. Yun H, Sun Z, Wu J, Tang A, Hu M, Xiang Z. Laboratory data analysis of novel coronavirus (COVID-19) screening in 2510 patients. Clin Chim Acta. 2020;507:94-7.

8. Ramirez GA, Yacoub MR, Ripa M, Mannina D, Cariddi A,
Saporiti N, et al.. Eosinophils from physiology to disease: A comprehensive review. Biomed Res Int. 2018;2018:9095275.

9. Lindsley AW, Schwartz JT, Rothenberg ME. Eosinophil responses during COVID-19 infections and coronavirus vaccination. J Allergy Clin Immunol. 2020;146:1-7.

10. Weller PF, Spencer LA. Functions of tissue-resident eosinophils. Nat Rev Immun. 2017;17:746-60.

11. Ajeneye F, Olofin O. Eosinopenia as a diagnostic marker in Covid-19. Hematol Blood Disord. 2020;2:31-3.

12. Kermali M, Khalsa RK, Pillai K, Ismail Z, Harky A. The role of biomarkers in diagnosis of COVID-19-A systematic review. Life sciences. 2020;13:117788.

13. Hozhabri H, Piceci Sparascio F, Sohrabi H, Mousavifar L, Roy R, Scribano D, et al.. The global emergency of novel coronavirus (SARS-CoV-2): An update of the current status and forecasting. Int J Environ Res Public Health. 2020;17:5648.

14. Singhal T. A review of coronavirus disease-2019 (COVID-19). Ind J Ped. 2020;87:281-6.

15. Malik P, Patel U, Mehta D, Patel N, Kelkar R, Akrmah M, et al.. Biomarkers and outcomes of COVID-19 hospitalisations: Systematic review and meta-analysis. BMJ Evid Based Med. 2020;bmjebm-2020-111536.

16. Giacomelli A, Pezzati L, Conti F, Bernacchia D, Siano M, Oreni L, et al. Self-reported olfactory and taste disorders in patients with severe acute respiratory coronavirus 2 infection: A cross-sectional study. Clin Infect Dis. 2020;71:889-90.

17. Chen N, Zhou M, Dong X, Qu J, Gong F, Han Y, et al.. Epidemiological and clinical characteristics of 99 cases of 2019 novel coronavirus pneumonia in Wuhan, China: A descriptive study. Lancet. 2020;395:507-13.

18. Mahgoub D, El Taydy AM, Makari M, Rashed L. Toll 7 and Toll 9 in psoriasis vulgaris before and after phototherapy. Our Dermatol Online. 2014:5:129-34

19. Drake MG, Bivins-Smith ER, Proskocil BJ, Nie Z, Scott GD, Lee JJ, et al.. Human and mouse eosinophils have antiviral activity against parainfluenza virus. Am J Respir Cell Mol Biol. 2016;55:387-94.

20. Davoine F, Lacy P. Eosinophil cytokines, chemokines, and growth factors: Emerging roles in immunity. Front Immunol. 2014;5:570.

21. Zhao L, Zhang YP, Yang X, Liu X. Eosinopenia is associated with greater severity in patients with coronavirus disease 2019. Allergy. 2021;76:562-4.

22. Tian S, Hu W, Niu L, Liu H, Xu H, Xiao SY. Pulmonary pathology of early-phase 2019 novel coronavirus (COVID-19) pneumonia in two patients with lung cancer. J Thorac Oncol. 2020;15:700-4.

Copyright by Farhana Tahseen Taj, et al.. This is an open-access article distributed under the terms of the Creative Commons Attribution License, which permits unrestricted use, distribution, and reproduction in any medium, provided the original author and source are credited.

Source of Support: Nil, Conflict of Interest: None declared. 